\title{
Identity in Memory: Ascertaining Consciousness beyond Dementia
}

\section{Duncan $\mathrm{AC}^{*}$}

Neuropsychiatric Research Center of Southwest Florida, Florida, USA

*Corresponding author: Duncan AC, Neuropsychiatric Research Center of Southwest Florida, Florida, USA, Tel: +1 239-939-7777, E-mail: acduncan@nprc-swfl.com

Citation: Duncan AC (2018) Identity in Memory: Ascertaining Consciousness beyond Dementia. J Neurol Neurol Disord 4(3): 302. doi: 10.15744/2454-4981.4.302. doi: 10.15744/2454-4981.4.302

Received Date: December 6, 2018 Accepted Date: December 28, 2018 Published Date: December 31, 2018

In the social jungle of human existence, there is no feeling of being alive without a sense of identity. $\sim$ Erik Erikson

Identity formation comes in various definitions within psychology, neurobiology and spiritual worlds, but universally, it may be agreed that identity is a part of having a sense of self-awareness about who we are as individuals. As humans' feel, think, sense and experience life in their surroundings, memory deposits formulate. Some argue that it is our memories that define who we are, but what happens when memory is disrupted with a dementia, such as, Alzheimer's disease (AD)? As persons living with AD or a related dementia experience memory loss, too often, care providers tend to wane in recognizing the person as they treat the disease. Oftentimes, physicians, family, friends and society at large are inclined to talk around the person with the diagnosis as if they were not in the room, speaking directly to their counterpart. Even some with an early diagnosis of AD may take on the disease as their identity, as a 58 year old an accountant with Early Onset AD questioned, "Without my memories, who am I?"

Erik Erikson built his career studying life stage development, and from the first stage of birth to the eighth and final stage of life, he perceived all to maintain a sense of identity (Davey, 2014) [1]. Few in the medical community treat dementia in lieu of Erik Erikson's theory of identity. The neurological complexities of AD often leave caregivers with an attitude that as the disease progresses, so too does the identity of the person living with AD: “Tom Kitwood coined the term, 'malignant social psychology' to describe ways in which the personhood of people with dementia is undermined in day to day interactions with caregivers and others" (Little, 2002 p41-42) [2].

First discovered in 1906 by German psychiatrist and neuropathologist, Alois Alzheimer, he observed Aguste Deter, a patient of his from a Berlin insane asylum. Deter had rapid deteriorating memory loss and he was intrigued by her symptoms. When Deter died Alzheimer's was able to examine her brain under a microscope with a new staining technique and found the plaques (amyloid) and tangles (tau) proteins engulfed in her Brain (Little, 2002) [2]. Despite Detour's advances in dementia, she was able to still recognize parts of herself. In taking a closer look at the beginning case of Auguste Deter, when Alzheimer's first assessed her, she knew who she was.

On November 26, 1901, Alois describes in his medical notes upon his assessment of Deter, "What is your name? Auguste. Last name? Auguste. What is your husband's name? Auguste, I think. Your husband? Ah, my husband. She looks as if she didn't understand the question. Are you married? To Auguste. Mrs D? Yes, yes, Auguste D...” (Maurer, 1997 p1547) [3].

Despite Deter's confusion and progressing condition, she knew her name, a form of her identity. Much has advanced in AD research since 1906; however, what has not seemed to change is the perception that those with AD lack a sense of identity. As a result in not fully supporting one's autonomy, quality of life is diminished. Oftentimes, those in the early stages of the disease tend to find the reality unbearable to accept. Common responses when counseling individuals throughout the Unites States are, "I am losing myself. My memories are who I am and without my mind, who am I?" The more cognizant the person is in the beginning stages of dementia, typically, the harder it is to digest. As in the book, Still Alice, the character of Alice starts to experience memory loss that affects her prestigious faculty position as a Harvard professor and panic sets in as she gets lost on a routine run she has done numerous times in Harvard Square. As she is coping with a diagnosis of Alzheimer's disease, losing her memory is a terrifying experience. Terrifying enough that she writes out a suicide note and refers to it daily in keeping track of her memory through her diary. She has a plan of killing herself when she believes her mind has come to the point of total failure in remembering (Genova, 2007). Ironically, as the disease progresses, the suicide note becomes a forgotten memory and as Alice slips deeper into advancing Alzheimer's, she becomes complacent.

Families too, struggle with the disease in seeing their loved one's memory fade. In the beginning stages of memory lapses denial is a common phenomenon, which tends to get tougher for families to cope with as the disease advances. Spouses tend to transform into caregivers as the loss of marital identity accompanies the disease and the person needs more care and supervision. Adult 
children often feel they have lost a parent, as they too tend to become caregivers in the process. Relationships change with the disease. It is common to hear families tell care staff, "This isn't my mother" when her mother has angry outbursts and may curse, "My mother never cursed her entire life- this isn't her." With perspective to relationships and its role, the way in which care is provided, shifts. In dementia residential placement, care staff is accustomed to caring for this population; however, the quality of care is frequently substandard due to the lack of understanding, compassion and training in Alzheimer's disease. Persons living with Alzheimer's are often dismissed with misconceptions that they are not in-tune of having self-awareness, or in their surroundings. As a result, abuse is rampant in dementia care, particularly in the United States where even physicians and other medical professionals tend to cease looking at their patient as human (Han, et al. 2014).

Alzheimer's has frequently been front-page news with more awareness of the disease, but the stigma in discussing it, understanding it, and caring for persons with it, remains insufficient. AD is the most feared disease among any other life threatening disease, including cancer, stroke, heart disease and diabetes (Andersen, 2013) [4]. One of the feared stigmas in AD is the inability to remember and losing one's memory. A common misconception in $\mathrm{AD}$ is that losing one's memory equals losing one's identity and self- awareness. As plaques and tangles diminish neurons, lessening the ability for one to live independently, the question of losing ones identity, despite having Alzheimer's disease begs to ask: Are neurons responsible in withholding ones identity?

Identity and the ego are inhibited with the frontal cortex (the part of the brain that acts as the executive director). It is the executive functioning portion that enables one how to think, reason, and formulate judgments (Rubial-Alvarez, et al. 2013) [5]. Experiences play a part into formulating identity, how we react/respond to our world (fight or flight). The frontotemporal lobe supports the ego on what is etiquette or politically correct when interacting and owning up to whom we are and what we believe. As amyloid and tau build up and spread throughout the brain, the frontotemporal lobe becomes affected, but does the damage to this area take away one's identity and sense of self?

Activity staff is responsible for incorporating therapeutic programs for their residents and usually have a substandard idea of various dementias, along with a dismal activity budget to provide dignifying activities that support personhood. These adults are too often treated as children with facilities looking more like a child's nursery with "Wheels on the Bus" playing in the background and childlike artwork hung on the walls, all looking alike with no individuation of who created what. By implementing adult, dignifying art materials the message may instill dignity, and can make a profound difference in creating a safe setting for selfexpression. With care not being up to par nationally, and the perception that this population lacks identity and self-awareness, medical communities will continue to provide mediocre and poor care in supporting their residents' quality of life. Identity is typically not acknowledged in the dementia population due to the common misperceptions that they have no self-awareness. Oftentimes, it is the CNA that assists with activities in addition to managing a resident's activies of daily living (ADL's). The burnout rate of care staff in $\mathrm{AD}$ is one of the highest, with staff often bouncing from one facility to another, and/or exhibiting negative behaviors i.e. depression, exhaustion and irritability due to working long hours, being sleep deprived, eating poorly, and not taking care of their own health. CNA's barely, if at all, receive any education in Alzheimer's disease and related dementias, and as a result, tend to lack the understanding and compassion needed in giving quality care.

$\mathrm{AD}$ care facilities are big profits for corporations in the caregiving business sector as there has been an increase in residential and home care companies rising across the country as the disease only increases. Too often, these places beautify their environments with lavish decorations, yet provide mediocre activities to support personhood. The majority of care costs are private pay, out of pocket expenses with the national average costing an American family \$6,600 per month in residential care, and home care options, also private pay, a national average of $\$ 20$ per hour (Paying For Senior Care, 2016) [6]. CNA's typically provide the most care and are paid an average of $\$ 9.81$ an hour, often working two and three other jobs in order to take care of themselves and their families (The Long-Term Workforce, 2016) [7]. The National Ombudsman Reporting System reviewed 1.4 million nursing home residents in the United States, with 835,200 in residential dementia care. This is an example of common national reports being published exposing mistreatment of residents within Alzheimer's nursing facilities and in home care companies (National Center on Elder Abuse, 2014).

The highest risk in dementia abuse reported was psychological abuse at $88.5 \%$, with neglect abuse at $29.5 \%$ and physical abuse at 19.7\% (Aging in Place, 2018) most likely due to the misperception that caregivers think of this population as demented [8], with no sense of identity, lacking personal insight and awareness of their surroundings and unaware of what is being said to them. They may be lacking the compassion and understanding of the disease and who the person is, resulting in not effectively communicating that leads to catastrophic outcomes. It is questioned if care providers took the time to know the person they were caring for, their personal history, memories that are preserved, and knowing they held personal identity and awareness, would they treat them with better respect? The ways in which caregivers and medical professionals are educated in Alzheimer's care often will reflect the kind of care they give. How one communicates to this population through caring in ADL's or through social activities, will affect quality of life in general. How we treat and support one another makes the difference. Identity of what a person likes or dislikes may or may not change, but who that person is spiritually, remains intact. "We are not human beings having a spiritual experience. We are spiritual beings having a human experience" as Pierre Teilhard de Chardin, a French Jesuit priest, philosopher and paleontologist said (Koelzer, 2013) [9]. 
Expressive art therapists include: music, art, drama, dance/movement, and research studies validate the benefits these therapeutic modalities provide in supporting personhood and quality of life. Expressive arts therapist possesses the educational and credentialed qualifications in their medium. Those who specialize in Alzheimer's disease and related dementias have an advantage because they understand the empowerment behind the inner workings of nurturing the soul through creativity and its impact on the brain. Expressive art therapists also perceive their clients as human beings and recognize each person's unique identity. Unfortunately, art therapists are not utilized to the degree to make an impression in caregiving standards due to several factors: 1 . Care staff commonly have a misconception they can act as an Art Therapist and replicate such qualifications, only causing insult to those they are caring for by not being able to uphold such groups. 2. Artists' in the community looking to make a living will identify themselves as an art therapist without the proper education and training to withstand a successful group. 3. Activity budgets are often limited and the expense to compensate an art therapist isn't sufficient, as a result, such art therapy groups may only be held once a month, if at all. 4. Due to the high volume of staff turnover, an art therapist can get lost in the system and with new staff coming in, may not perceive the art therapy group as necessary and thus seceding the program.

CNA's typically assist the therapist during group activities, which may be helpful to not only the therapist, but to the participants being cared for. As care staff engages in art therapy programs, the sense of calm is usually felt, and connections in bonding relationships become established. Taking private practice sessions from around the United States, case studies that validate identity and self-awareness are exemplified.

\section{Case Study 1}

${ }^{*}$ Melinda, with advancing stages of Frontotemporal Lobe Dementia (FTD), resides in a dementia care facility. She was asked to think about what she was proud of and paint what came to her mind. She painted what she titled "The Lone Apple Tree" and when discussing this apple tree that ended up being a representation of her mother's orchid and love of cooking apple pies (Figure 1), cider and other apple pastries, began to discuss her proud moments of being an elementary school teacher and getting promoted to Principal, which she hated. She did not like being a disciplinary and said she preferred being a teacher. From that memory it unfolded about her marriage at an early age and asking herself if she was doing the right thing. She wondered if she had married too young in life. After raising a couple of children and loving her career, she came to the resolution that she married the right person. She spoke of the love she had for her husband and their life together in another state. Had Melinda's identity changed or was she stills the same person, despite living with FTD? The private duty aide who had been working with this woman for a year remarked, "I had no idea she was a teacher, or that she knew any of her past." The aide was engaged to be married herself and was facing her own fears. She began a conversation with Melinda about marriage, men and life. There was a noted shift in the way the aide was caring for Melinda with more gentleness and appreciation than seen in past times.

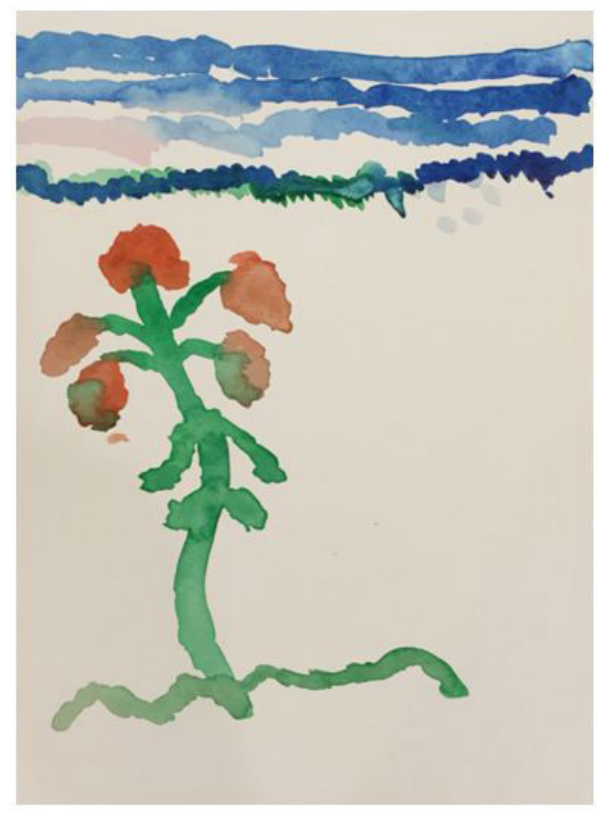

Figure 1: The Lone Apple Tree

Persons in the early stages of dementia commonly depict images reflecting fear, depression, anger, despair and concern. The more cognizant he or she is about the disease, the more apt he or she is to take on the identity of the disease itself, feeling as if they are losing their sense of self. Through the counseling process of validation, cognitive-behavioral therapy (CBT) and mindfulness practice taken from dialectical- behavioral therapy (DBT), tensions may ease and the reclaiming of the self is reinstated.

Usually, as the disease progresses more in the middle to moderate stages, and neurons are diminishing, the more complacent the person may become. Images reflect peaceful times, positive memories and the discussions of past times, i.e. professions, hobbies 
and passions take fruition. By the later stages of the disease, the brain is changing which usually affects spatial perception. Selfportraits, once seen as whole, typically become fragmented, as with the case of William Utermhlen [10], an American artist who resided in London, was diagnosed with Alzheimer's disease in 1995. He painted self portraits since his diagnosis until he wasn't able to, the last one completed in 2000 (Grady, 2006) [11]. Having the opportunity to observe his works while on display at the Capitol in Sacramento, California in the early 2000's, it was argued among medical professionals that his portraits looked as if he was losing his sense of identity. Because of the brain's disease process of shrinking, paintings and drawings appear limited; as if the person is depicting himself to be outwardly fading, leading viewers, such as those medical professionals, to assume the person has lost their sense of self. Rather, could it mean that the impaired brain is creating a rudimentary drawing of mere representation of the self, as commonly seen in a young child's drawing, instead of an identity being robbed?

It is common for persons with advancing stages of Alzheimer's disease to be compared to young children as the regression process often mimics the thoughts and behaviors of a child. In a study investigating young brains and those with Alzheimer's disease, researcher Jeffrey Lassig, M.D., of the University of Michigan found that, “Alzheimer's patients' white matter behaved more like the white matter of a child's brain than that of a normal adult" (2006, p15). In another study comparing cognitive and functional performance in children and those with Alzheimer's disease, investigating the retrogenesis model (a theory signifying that the brain of a person with Alzheimer's disease progresses in the reverse order that the brain developed from birth), found their study supported, "the inverse and progressive pattern of functional and cognitive decline observed in AD patients compared to the developmental acquisition of these capacities in children, as stated by the retrogenesis model" (Rubial-Alvarez, et al., 2013; 16) [4]. As a child's brain develops, parents and teachers, who also act as caregivers, often encourage growth, creativity and support the child's identity and self-awareness. They are seen as young and with a young mind, but are recognized and treated as a human being. Despite the brain changes of $\mathrm{AD}$, it needs to be addressed that holistically, these are adults with rich lives; they should be encouraged in their growth and treated with dignity as a human being.

The current drugs available on the market for $\mathrm{AD}$ are symptomatic medications and are not disease modifying. As clinical research in $\mathrm{AD}$ continues to investigate disease modifying treatments by slowing down and stopping disease progression, there remains to be no effective treatments to-date. The National Institute of Health $(\mathrm{NIH})$ receives mere drops in the bucket for AD research, and as $\mathrm{AD}$ continues to be one of the least funded diseases in research efforts, there is an alarming increase of persons being diagnosed every 65 seconds in the United States, with an expected estimation of reaching \$277 billion by the end of 2018 (Alzheimer's Association, 2018) [12]. Globally, 50 million people are living with AD and continuing to grow in diagnostic numbers as the largest population in the world are those 65 years and older with aging being a factor in AD (Alzheimer's Research UK, 2017) [13]. AD is the most costly in care treatment, taking up the most funding in Medicare and Medicaid within the United States, and the cost of pharmaceuticals is excessive, yet is more readily available and easily utilized as a "quick fix" as opposed to a less cost effective means of utilizing art, music or talk therapies. It takes time to have to utilize those outlets as opposed to a pill. Not all medications are bad and not needed as some are necessary, but to be relied upon to the extent of diminishing one's identity is not acceptable, nor responsible caregiving.

In the chaotic mess of dementia care in the United States, the focus on dollars spent to beautify the facility has taken the front seat as opposed to remembering why these businesses exist: taking are of the person in need, and with dignity and supporting their personhood. These dementia environments consisting of all administrators and staff need to understand that caring for another human being is to responsibly view their residents as humans and not over medicated zombies. By learning to acknowledge persons with dementia have identities and awareness, it is a responsibility to support their personhood, maintaining their integrity. John Locke, a $17^{\text {th }}$ century English philosopher and physician stated, "Personal identity depends on consciousness not on substance" (Nimbalkar, 2011 p268) [14].

Naomi Feil, MSW, developed Validation Therapy, a concept of validation, or the reciprocated communication of respect which communicates that the other's opinions are acknowledged, respected, heard, and (regardless whether or not the listener actually agrees with the content), they are being treated with genuine respect as a legitimate expression of their feelings, rather than marginalized or dismissed (Feil. 2017) [15]. Despite persons in the late stages of Alzheimer's disease, who are shut down and withdrawn inside themselves, Feil has been able to reach them by encouraging parts of their identity they resonate with and demonstrate that they are still there.

As an art therapist, I am often questioned as to why I would have persons with Alzheimer's disease create art, specifically, a selfportrait since it is believed they lack self-awareness. Despite disease progression, persons living with a dementia are typically able to create self-portraits and have meaningful conversations about who they are. This dialogue of exchange has surprised caregivers and family members who believed these past memories were lost, only to find rekindled life.

As one woman living in later stages of $\mathrm{AD}$ was asked to paint a picture of her, she sat quietly and looked to be in a deep thought. With support of putting the paintbrush in her hand she began to paint in silence. It wasn't until she was engaged with in a meaningful discussion that her memory revealed a definite purpose in her painting.

"Well, this is me at my home where I was a homemaker. I loved taking care of my children and my husband. I loved to cook, sew my children's clothes; I even sewed my own dresses. I love my family. This is me, the happy homemaker (Figure 2)." 


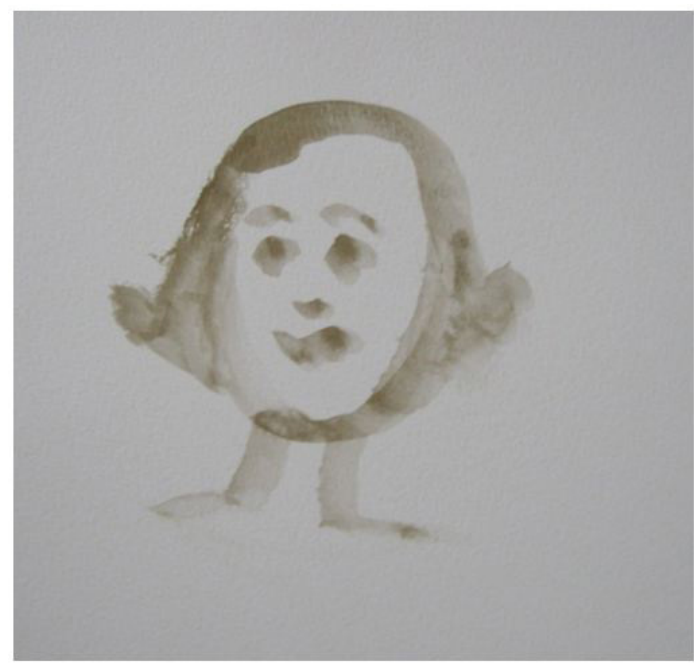

Figure 2: Happy Homemaker

For many with advancing Alzheimer's disease, the ability to use language dissipates but the ability to paint may remain intact, oftentimes, with hands-on guidance. That critical life-review stage continues as internal thoughts and emotions appear to be seen in the artwork. For loved ones and caregivers who know the affected person well, they can piece together and see things in the art that one who doesn't know the person well, may dismiss. Daniel C. Potts, MD, a neurologist whose father, Lester Potts, was a rural Alabama saw- miller that never created art until the diagnosis of Alzheimer's disease.

Lester was able to express himself and his sense of identity was established through his paintings. As Lester's words diminished and he became mute, one of his final paintings consisted of items that Lester self-identified with: a cross-saw that was known to Lester since his infancy, and one that he used throughout his career, his father's hat on a cross in a high-top boot that represented Lester's father's sense of self, along with images representing his passion of being in nature filled with trees, leaves and the birdhouses he would construct (Figure 3).

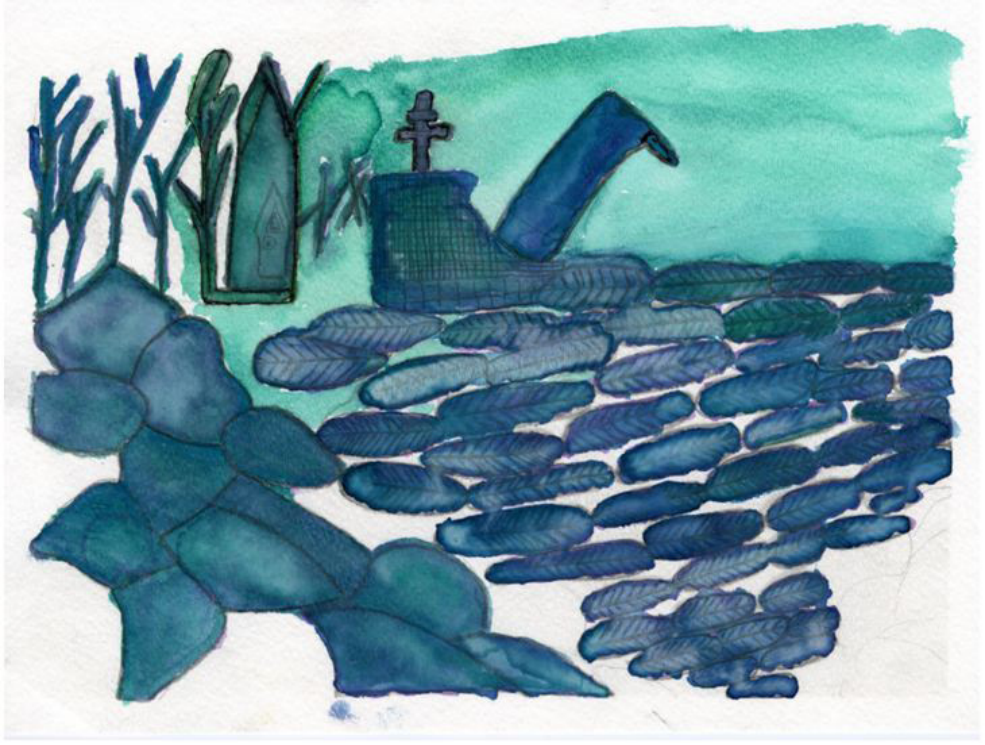

Figure 3

The late Gene Cohen, M.D., was among one of the first physicians to conduct a study, Research on Creativity and Aging: The Positive Impact of the Arts on Health and Illness on how the arts benefits both persons with and without dementia. Cohen concluded that providing expressive arts lowered doctor visits, lessened medication usages, increased morale and lowered depressive symptoms (Cohen, 2006) [16,17]. Neuropsychiatrist, Marc Agronin, M.D., Vice President- Behavioral Health and Clinical Research at the Miami Jewish Health System, advocates the importance of utilizing creativity. In his books, How We Age and The End of Old Age, Agronin beautifully exemplifies how and why the arts are imperative as a needed medicine. There remains a need for physicians to embrace, utilize and prescribe expressive arts therapy, combining both a medical and psychosocial model in meeting their patients' overall health in mind and body. In order for persons living with Alzheimer's or other types of dementia to thrive in life, we need to come to the conclusion that all human beings are that, human, and need to be treated as such. 


\section{References}

1. Davey K (2014) Erikson's Stages of Development. Learning Theories.

2. Little D (2002) Dementia: A Developmental Approach on Personhood and Spirituality. Geriatrics \& Aging 5: 41-2.

3. Maurer K, Volk S, Gerbaldo H (1997) Auguste D and Alzheimer's disease. Lancet 349: 1546-9.

4. Andersen E (2012) Americans Rank Alzheimer's as Most Feared Disease. The Lincoln Star.

5. Rubial-Álvarez S, de Sola S, Machado MC, Sintas E, Böhm P, et al. (2013) The comparison of cognitive and functional performance in children and Alzheimer's disease supports the retrogensis model. J Alzheimer's Dis 33: 191-203.

6. Paying for Senior Care (2016) Payment Options \& Financial Assistance for Alzheimer's Dementia Care.

7. Leading Age Wisconsin (2016) The Long-Term Care Workforce Crisis: A 2016 Report.

8. Aging in Place (2018) Guide to Recognize Elder Abuse and Knowing Your Rights.

9. Koelzer B (2013) We Are Spiritual Beings Having a Human Experience.

10. William Utermohlen (2017) Self-Portraits- Featured Articles.

11. Grady D (2006) Self-Portraits Chronicle a Descent into Alzheimer's. The New York Times, USA.

12. Alzheimer's Association (2018) Use and costs of healthcare, long-term care and hospice. The Alzheimer's Disease Facts \& Figures 14: 43-4.

13. Alzheimer's Research UK (2017) Global Prevalence.

14. Nimbalkar N (2011) John Locke on Personal Identity. Mens Sana Monogr 9: 268-75.

15. Feil N (2017) Validation.

16. Cohen G (2006) Research on Creativity and Aging: The Positive Impact of the Arts on Health and Illness. Generations XXX: 7-15.

17. Cohen G, Perlstein S, Chapline J, Kelly J, Firth KM, et al. (2006) The impact of professionally conducted cultural programs on the physical health, mental health, and social functioning of older adults. Gerontologist 46: 726-34.

18. Alzheimer’s Disease International (2017) Alois Alzheimer: The Global Voice on Dementia.

19. Erikson E (1982) Major stages in psychosocial development. The Life Cycle Completed: A Review. WW Norton and Company 1982: 61-6.

20. Indeed (2017) Apple Grove Alzheimer's \& Dementia Residence.

21. WebMD (2003) Alzheimer's Brain Similar to Child's: Discovery May Give Clues About Cause of Alzheimer's Disease.

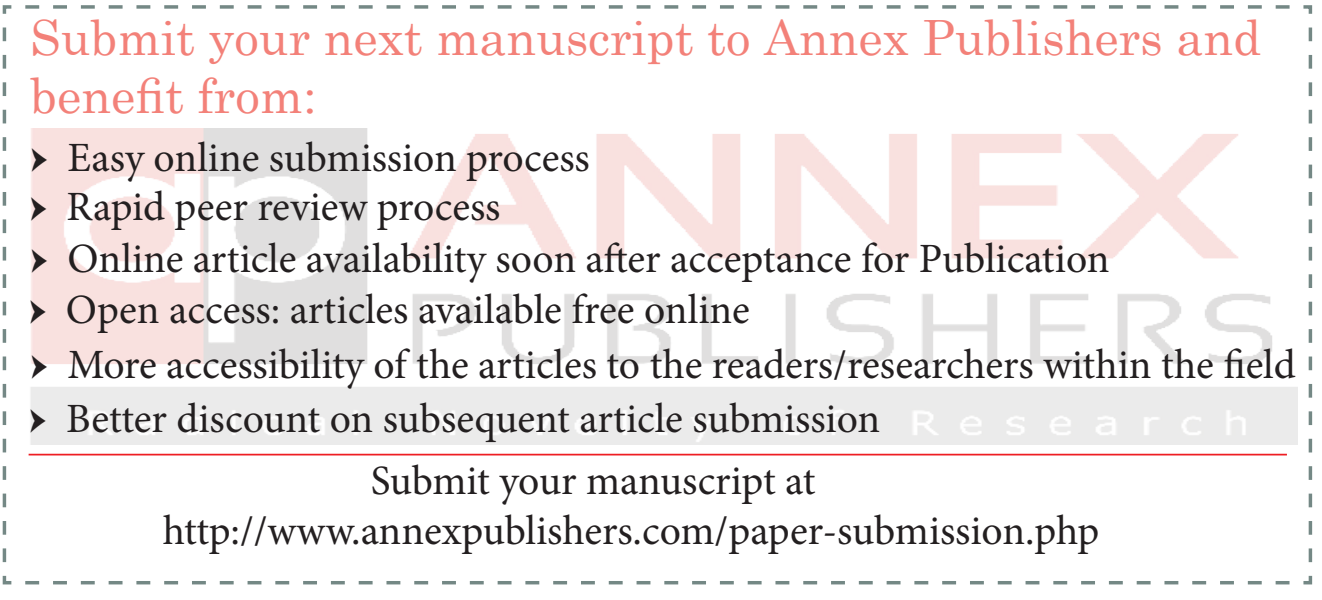

